\title{
Analisa Sistem Informasi untuk Proses Permintaan Data pada Universitas XYZ
}

\author{
Angellia Debora Suryawan, Veronica \\ Information System Department, Bina Nusantara University, Jakarta, Indonesia \\ asuryawan@binus.edu,veronica@binus.edu \\ Diterima 1 September 2015 \\ Disetujui 16 Oktober 2016
}

\begin{abstract}
Data is very important component in the organization and should be managed properly. Information with accurate, precise, and reliable data be beneficial for the organization for decision making. XYZ University realize that the data management is very important process. The needs of data must be supported properly and quickly, so that the required data can be accessed anytime and anywhere. In this study discusses the process of providing data according to user demand. The method in this paper is identification, define the problem, and data collection. XYZ University already has applications to support data requests, but not all data requests can be fulfilled in the system. There is still a process of data requests made through emails. Overall, the application for data requests very helpful for database and system admin staff, so the routine data requests through emails can be reduced. The application has also features for monitoring data requests from units, so the Manager can monitor the process of the data request and find out any unit that doing frequent data requests each month. But, the application also required for tracking data requests, so user can monitor status of data requests, who's working on, and estimation time for processing data requests.
\end{abstract}

Index Terms - data, data request, database, information system

\section{PENDAHULUAN}

\section{I.1. Latar Belakang}

Sistem informasi saat ini sudah menjadi hal yang umum dan kebutuhan dalam sebuah organisasi. Sistem informasi digunakan untuk menunjang dan mendukung proses bisnis agar proses bisnis bisa berjalan dengan efektif dan efisien. Untuk membuat sistem informasi yang terintegrasi diperlukan budget yang tidak sedikit, karena harus dipastikan bahwa sistem informasi yang dikembangkan dan diimplementasikan memberikan keuntungan bagi organisasi.

Sistem informasi yang dikelola dengan baik akan memberikan keuntungan bagi organisasi, yaitu membuat proses operasional perusahaan menjadi lebih cepat, akurat, dan terintegrasi. Selain itu, sistem informasi bisa mendukung dalam pencapaian strategi organisasi, sehingga organisasi bisa kompetitif dalam persaingan bisnisnya.

Untuk menilai sistem informasi, dulu organisasi mengukur melalui cara finansial seperti return of investment [1]. Kemudian berkembang dan diketahui bahwa ada keuntungan nyata dan tidak nyata dari sistem informasi, maka organisasi menggunakan metode balanced scorecards [2] dan benchmarking [3].

Pada paper ini akan dibahas penilaian dan analisa sistem informasi pada Universitas XYZ menggunakan metode balanced scorecards. Analisa dilakukan pada divisi IT dibagian database \& system admin yang melayani proses permintaan data yang ada di database Universitas XYZ untuk mendukung proses bisnis organisasi. Proses permintaan data biasa didapat melalui email dari divisi lain untuk memenuhi kebutuhan mereka.

I.2. Tujuan

Tujuan yang ingin dicapai dari penelitian ini diantaranya:

1. Melakukan analisis terhadap Universitas dan Divisi IT menggunakan Balanced Scorecards.

2. Melakukan analisis terhadap masalah permintaan data.

3. Membangun sistem informasi untuk permintaan data. 


\section{METODE PENELITIAN}

\subsection{Identifikasi dan Perumusan Masalah}

Masalah yang ada pada saat ini adalah proses permintaan data dilakukan melalui email, dan terkadang beberapa bagian meminta data dengan format yang sama secara berulang-ulang dalam periode waktu tertentu, sehingga bagian database \& system admin harus menarik data yang sama secara berulang kali. User juga kesulitan melakukan tracking permintaan data, sehingga tidak diketahui status pengerjaan permintaan data tersebut. Belum adanya SLA (Service Level Agreement) yang jelas untuk mengukur kinerja staf yang melayani permintaan data.

\subsection{Pengumpulan Data}

Pada studi kasus ini pengumpulan data diperoleh dari :

\section{Studi Pustaka}

Studi pustaka dilakukan untuk mendapatkan teori-teori yang berhubungan dan mendukung penulisan pada paper ini. Bahan studi pustaka didapat dari jurnal-jurnal, artikel, buku, maupun referensi lainnya yang membantu dalam proses pengolahan dan analisa data.

\section{Penelitian Terdahulu}

Penelitian terdahulu merupakan referensi untuk penulisan paper ini dan dijadikan acuan dalam mendapatkan informasi yang dibutuhkan.

\section{PEMBAHASAN}

\subsection{Balanced Scorecards}

Balanced scorecards menyediakan framework untuk perubahan organisasi melalui eksekusi strategi. Balanced Scorecards berbeda karena didalamnya menghubungkan penyebab dan dampak pada setiap bagian organisasi, sehingga visi dan strategi organisasi jelas dan dimengerti oleh setiap anggota organisasi.

Balanced Scorecard menterjemahkan visi dan strategi organisasi kedalam seperangkat ukuran yang menyeluruh yang memberi kerangka kerja bagi pengukuran dan sistem manajemen strategis [2].
Pada saat pertama kali dikenalkannya konsep balanced scorecard pada tahun 1990 oleh Robert S kaplan dan David P. Norton [2], balanced scorecard hanya digunakan sebagai alat pengukuran kinerja pada organisasi bisnis. Balanced scorecard sebagai suatu sistem pengukuran kinerja dapat digunakan sebagai alat pengendalian, analisa, dan merevisi strategi organisasi [4]. Balanced scorecard dapat membantu organisasi dalam mengontrol keuangan dan mengukur kinerja organisasi [5]. Pengukuran kinerja pada organisasi dapat meningkatkan pertanggungjawaban dan memperbaiki proses pengambilan [6].

Balanced scorecard merupakan sistem manajemen strategis yang menterjemahkan visi dan strategi suatu organisasi kedalam tujuan dan ukuran operasional [7]. Tujuan dan ukuran operasional tersebut kemudian dinyatakan dalam empat perspektif yaitu perspektif finansial, pelanggan (customers), proses bisnis internal, serta pembelajaran dan pertumbuhan (learning and growth) [2]. Berdasarkan keempat kategori tersebut, finansial, customer, proses internal, dan learning and growth membantu manager tidak hanya fokus pada penilaian dan perhitungan kinerja finansial [8].

Ketika balanced scorecard dilihat sebagai tool untuk mendefinisikan, mengeksekusi, dan strategi penilaian, implementasi balanced scorecard juga digunakan untuk membuat keputusan tepat dalam pengambilan keputusan dan perencanaan untuk mencapat strategi tersebut [8]. Kaplan \& Norton [2] menyarankan bahwa pengembangan balanced scorecard akan menjadi usaha penggabungan pihak manajer unit dan upper management.

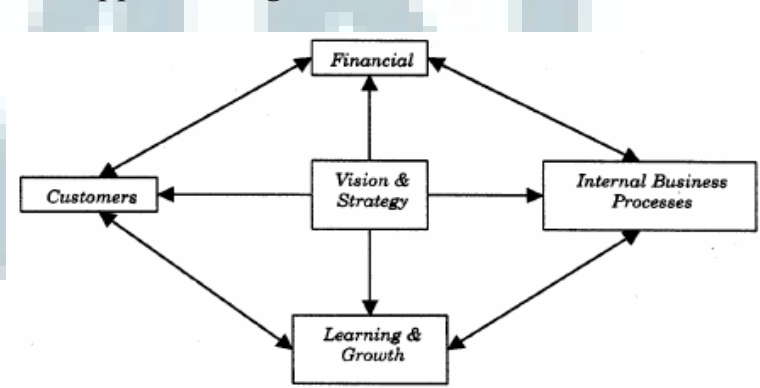

(Sumber: Rohm 2003)

Gambar 1. Balanced Scorecards

3.2. Pembahasan Balanced Scorecards Menurut 
Kaplan \& Norton

Berikut analisa balanced scorecard pada Universitas XYZ :

- Visi dan strategi organisasi

Visi : "A World-class university ... In continuous pursuit of innovation and enterprise"

Untuk mencapai visi tersebut, Universitas XYZ mempunyai misi untuk berkontribusi pada komunitas global melalui ketentuan/prosedur pendidikan kelas dunia, dengan cara :

1. Recognizing and rewarding the most creative and value-adding talents

2. Providing a world-class teaching, learning and research experience that fosters excellence in scholarship, innovation and entrepreneurship.

3. Creating outstanding leaders for global community

4. Conducting professional services with an emphasis on application of knowledge to the society

5. Improving the quality of life of Indonesians and the international community Database \& system admin membantu organisasi dalam menunjang dan mendukung pemberian informasi yang dibutuhkan untuk mencapai visi tersebut. Dengan memberikan informasi sesuai kebutuhan, cepat, dan akurat akan mendukung organisasi dalam proses pengambilan keputusan untuk menghasilkan strategi yang cepat dan kompetitif.

- $\quad$ Finansial

Tujuan dan ukuran keberhasilan finansial dari setiap implementasi sistem informasi yang mendukung strategi organisasi adalah minimal menghasilkan Return On Investment (ROI), bahkan kalau bisa menghasilkan keuntungan bagi organisasi, baik keuntungan yang tangible atau non tangible. Setiap impelementasi harus di montoring kebutuhan dan kinerja finasialnya. Sasarannya adalah implementasi sistem informasi yang sesuai dengan kebutuhan organisasi dan bisa membantu organisasi dalam mendukung pencapaian visi dan strategi organisasi. Strategi dan eksekusi strategi yang baik, pasti memberikan hasil finansial yang baik bagi organisasi. Sehingga setiap biaya yang dikeluarkan organisasi tidak sia- sia dan memberikan keuntunhan bagi organisasi.

\section{- Customer}

Customer untuk Universitas XYZ adalah mahasiswa, orang tua mahasiswa, calon mahasiswa, dan pihak-pihak lain yang bekerja sama dengan Universitas XYZ. Untuk mencapai visi tersebut, Universitas XYZ harus memberikan pelayanan yang memuaskan customer, memenuhi ekspetasi customer terhadap Universitas XYZ, memberikan servis dan produk terbaik, dan terus mencari customer baru. Untuk mencapai visi tersebut, Universitas XYZ harus memberikan pendidikan yang sesuai dengan kurikulum kelas dunia (contohnya : smart class), bekerja sama dengan perguruan tinggi di Negara lain (pertukaran mahasiswa), menyediakan tenaga pengajar yang kompeten, memberikan fasilitas dan sarana yang menunjang proses belajar dan mengajar, serta mempunyai sistem informasi yang mendukung proses bisnis organisasi, sehingga proses bisnis organisasi baik front end dan back end dapat berjalan dengan efektif dan efisien.

Untuk mencari calon mahasiswa baru dibutuhkan analisa informasi yang ada, sehingga bisa dilihat tren data dan hal tersebut sangat bermanfaat untuk marketing dalam menentukan strategi marketing untuk mendapatkan mahasiswa baru.

- $\quad$ Proses bisnis internal

Proses bisnis internal diperlukan untuk mengidentifikasi dan menilai proses-proses yang penting bagi organisasi dalam melayani kebutuhan stakeholder dan customer. Tujuan dari proses bisnis internal adalah mengembangkan proses bisnis yangs sesuai dengan visi dan strategi organisasi, dan membuat proses bisnis yang sudah ada menjadi lebih cepat, efektif, dan efisien lagi (kualitas proses lebih bagus dengan waktu yang lebih singkat). Diperlukan juga adanya inovasi dalam proses bisnis yang ada, sehingga menjadikan organisasi menjadi kompetitif dalam persaingan didunia bisnis. Dengan adanya ketersediaan informasi yang tepat dan cepat, maka pihak manajemen bisa mengambil langkah strategi baru untuk keuntungan organisasi. Waktu dalam proses pelayanan juga dibuat seoptimal mungkin, sehingga bisa meningkatkan kepuasan 
customer.

\section{- $\quad$ Learning and growth}

Untuk mencapai visi dan strategi organisasi, maka diperlukan kemampuan organisasi dan anggota organisasi untuk mengikuti perkembangan dan persaingan dalam dunia pendidikan, agar bisa menjadi perguruan tinggi kelas dunia. Untuk meningkatkan diri, Universitas XYZ terus mengikuti perkembangan dalam dunia pendidikan dan IT. Universitas XYZ terus mengembangkan dan menyediakan sarana IT yang up to date untuk mendukung proses bisnis dan pembelajaran. Sehingga proses pembelajaran dan bisnis menjadi otomatis dan optimal. Universitas XYZ juga memberikan pelatihan untuk para anggota organisasi (karyawan dan dosen), agar mempunyai anggota organisasi yang kompetitif dan berkualitas mengikuti perkembangan pasar yang ada.

\subsection{Pembahasan Balanced Scorecards Menurut Grembergen}

Menurut Grembergen, konsep Balance Scorecard yang dikembangkan oleh Kaplan dan Norton [2] dapat diimplementasikan ke fungsi TI dan proses-prosesnya sehingga timbul konsep Information Technology Balance Scorecard. Implementasi Balance Scorecard pada fungsi TI ini menjadi tool yang semakin popular digunakan oleh perusahaan-perusahaan. IT Balance Scorecard terbagi menjadi empat faktor, yaitu:

- Kontribusi Perusahaan Contribution)

- Orientasi Pengguna (User Orientation)

- Penyempurnaan Operasional (Operational Excellent)

- Orientasi Masa Depan (Future Orientation)

Berikut adalah tabel balanced scorecard Universitas secara umum.yang dapat diimplementasikan:

Tabel 1. Balanced Scorecards

\begin{tabular}{|c|c|c|c|c|}
\hline \multirow{4}{*}{$\begin{array}{l}\text { Financial : to succeed } \\
\text { financially how } \\
\text { should we appear to } \\
\text { our shareholders? }\end{array}$} & Objectives & Measures & Targets & Initiatives \\
\hline & $\begin{array}{l}\text { Memberikan keuntungan } \\
\text { maksimal }\end{array}$ & $\begin{array}{l}\text { Return On Investment } \\
\text { (ROI) }\end{array}$ & $90 \%$ & Tracking cost dan budget \\
\hline & Utilization of assets & Utilization Rates & $10 \%$ & Tracking assets \\
\hline & Peningkatan pendapatan & $\begin{array}{l}\text { Persentase selisih } \\
\text { pendapatan }\end{array}$ & $+10 \%$ & $\begin{array}{l}\text { Mengadakan kegiatan } \\
\text { open house di Universitas } \\
\text { XYZ }\end{array}$ \\
\hline \multirow{4}{*}{$\begin{array}{l}\text { Customer : to } \\
\text { achieve our vision } \\
\text { how should we } \\
\text { appear to our } \\
\text { customers? }\end{array}$} & Customer retention & $\begin{array}{l}\text { Jumlah mahasiswa aktif } \\
\text { dan penurunan NR }\end{array}$ & $2 \%$ & $\begin{array}{l}\text { Customer Relations } \\
\text { Management (CRM) }\end{array}$ \\
\hline & Customer service & Kuesioner dan survey & $90 \%$ & $\begin{array}{l}\text { Customer Relations } \\
\text { Management (CRM) }\end{array}$ \\
\hline & Customer relation & $\begin{array}{l}\text { Persentase feedback dari } \\
\text { orangtua mahasiswa }\end{array}$ & $30 \%$ & $\begin{array}{l}\text { Customer Relations } \\
\text { Management (CRM) }\end{array}$ \\
\hline & $\begin{array}{l}\text { Peningkatan jumlah } \\
\text { mahasiswa baru }\end{array}$ & Persentase mahasiswa baru & $+10 \%$ & $\begin{array}{l}\text { Mengadakan kegiatan } \\
\text { open house di Universitas } \\
\text { XYZ }\end{array}$ \\
\hline \multirow{4}{*}{$\begin{array}{l}\text { Internal Business } \\
\text { Processes : to satisfy } \\
\text { our shareholders and } \\
\text { customers, at what } \\
\text { business processes } \\
\text { must we excel? }\end{array}$} & Kecepatan dalam servis & Waktu servis & 15 menit & $\begin{array}{l}\text { Business Proces } \\
\text { Rengineering (BPR) }\end{array}$ \\
\hline & Servis yang efektif & $\begin{array}{l}\text { Solusi untuk pemecahan } \\
\text { masalah }\end{array}$ & $70 \%$ & $\begin{array}{l}\text { Customer Relations } \\
\text { Management (CRM) }\end{array}$ \\
\hline & Optimal cost & Persentase biaya servis & $67 \%$ & $\begin{array}{l}\text { Business Proces } \\
\text { Rengineering (BPR) }\end{array}$ \\
\hline & Resource utilization & Persentase produktifitas & $80 \%$ & $\begin{array}{l}\text { Business Proces } \\
\text { Rengineering (BPR) }\end{array}$ \\
\hline \multirow{2}{*}{$\begin{array}{l}\text { Learning and } \\
\text { Growth : to achieve } \\
\text { our vision, how } \\
\text { will we sustain our } \\
\text { ability to change and } \\
\text { improve? }\end{array}$} & $\begin{array}{l}\text { Peningkatan level } \\
\text { kemampuan dosen dan } \\
\text { karyawan }\end{array}$ & $\begin{array}{l}\text { Assessment dan pelatihan } \\
\text { karyawan dan dosen }\end{array}$ & $75 \%$ & $\begin{array}{l}\text { Corporate University } \\
\text { untuk learning, traning, } \\
\text { dan assessment karyawan } \\
\text { dan dosen }\end{array}$ \\
\hline & $\begin{array}{l}\text { Kepuasan karyawan dan } \\
\text { dosen }\end{array}$ & Kuesioner dan survey & $75 \%$ & Quality time initiative \\
\hline
\end{tabular}




\section{\begin{tabular}{|c|c|}
\hline $\begin{array}{c}\text { User Orientation } \\
\text { How do the users view } \\
\text { the IT department? }\end{array}$ & $\begin{array}{c}\text { Corporate Contribution } \\
\text { How does management } \\
\text { view the IT department? }\end{array}$ \\
\hline $\begin{array}{l}\text { Operational Excellence } \\
\text { How effective and efficient } \\
\text { are the IT processes? }\end{array}$ & $\begin{array}{c}\text { Future Orientation } \\
\text { Is IT positioned to meet } \\
\text { future challenges? }\end{array}$ \\
\hline \multicolumn{2}{|c|}{ Gambar 2. IT Balanced Scorecards }
\end{tabular}}

Berikut adalah standar BSC untuk menganalisis sistem informasi permintaan data di Universitas:

Tabel 2. IT Balanced Scorecards - User Orientation

\begin{tabular}{|l|}
\hline User Orientation \\
\hline How do the users view the IT department? \\
\hline Mission \\
\hline $\begin{array}{l}\text { IT sebagai "helper", yaitu mendukung proses bisnis, serta } \\
\text { pemanfaatan aset dan kesempatan bisnis secara maksimal } \\
\text { dengan bantuan IT, termasuk menyiapkan data sesuai } \\
\text { permintaan dan kebutuhan Universitas. }\end{array}$ \\
\hline Objectives \\
\hline - kepuasan user \\
- hubungan baik dengan user \\
- preferred supplier \\
\hline
\end{tabular}

Tabel 3. IT Balanced Scorecards - Corporate Contribution

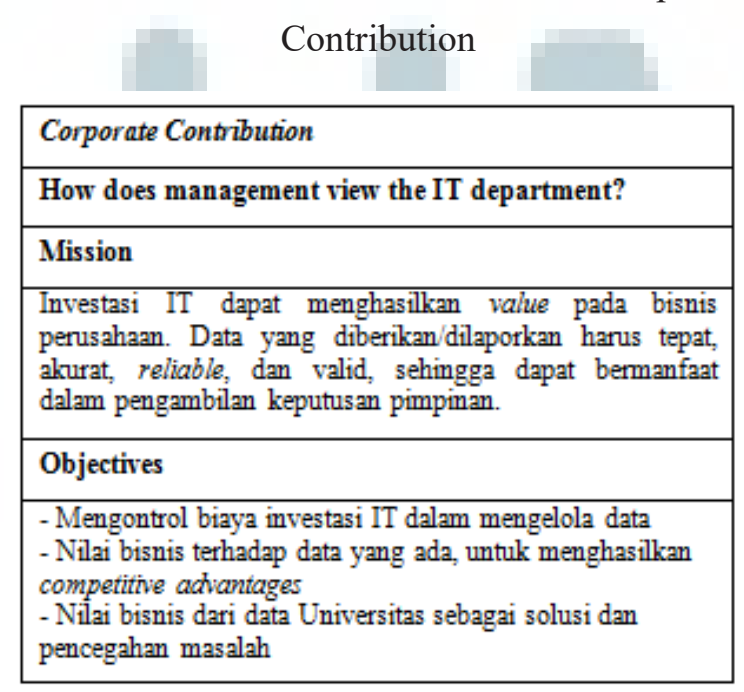

Tabel 4. IT Balanced Scorecards - Operational Exellence

\begin{tabular}{|c|}
\hline How effective are the IT processes? \\
\hline Mission \\
\hline $\begin{array}{l}\text { Secara efisien dalam memberikan servis IT dan produk IT } \\
\text { terutama dalam penyediaan data Universitas }\end{array}$ \\
\hline Objectives \\
\hline $\begin{array}{l}\text { - Pengembangan dan membangun aplikasi permintaan data } \\
\text { yang efisien } \\
\text { - Operasi computer/server yang cepat dan aman } \\
\text { - Sebagai fungsi help desk yang efisien } \\
\text { - Pendukung proses bisnis yang efisien }\end{array}$ \\
\hline
\end{tabular}

Tabel 5. IT Balanced Scorecards - Future Orientation

\begin{tabular}{|l|}
\hline Is IT positioned to meet future challenges \\
\hline Mission \\
\hline $\begin{array}{l}\text { Mendukung Universitas dalam menghadapi tantangan masa } \\
\text { depan dan menjadi Universitas yang kompetitif dalam } \\
\text { persaingan bisnis }\end{array}$ \\
\hline Objectives \\
\hline - Mengadakan training dan pendidikan yang sesuai untuk \\
staf database \& system admin \\
- Mengembangkan keahlian staf database \& system \\
admin \\
- Penelitian terhadap teknologi IT yang baru \\
- Membuat portfolio database \& system admin \\
\hline
\end{tabular}

\subsection{Database \& System Admin}

Database \& system admin adalah bagian dari divisi IT yang melayani permintaan data dan informasi dari divisi lain, maupun divisi internal IT sendiri sesuai dengan kebutuhan organisasi. Permintaan data dari user dilakukan melalui email kepada database \& system admin. Setiap harinya banyak permintaan data, baik permintaan data dan informasi yang rutin (seperti : pendaftar msdnaa, pendaftar email dosen, data mahasiswa aktif, dan sebagainya), maupun data tidak rutin (seperti : hasil kuesioner dosen, data nilai, dan sebagainya). Data tersebut sangat penting untuk 
divisi lain dalam mendukung proses bisnis mereka.

Setiap hari terdapat banyak permintaan data dan informasi mengenai data yang dibutuhkan dari berbagai divisi. Dan kadang permintaan tersebut diminta berulang-ulang, misal permintaan mahasiswa aktif yang setiap harinya bisa berubah, maka pihak layanan mahasiswa selalu meminta data mahasiswa aktif perharinya untuk mengecek status dan jumlah mahasiswa aktif yang ada.

Permintaan data melalui email juga tidak bisa ditelusuri lama pengerjaannya. Sehingga pada saat banyak email permintaan data dari berbagai divisi, pengerjaannya bisa menghabiskan waktu berhari-hari dan kadang terlupakan. Hal ini membuat user menjadi tidak puas dengan pelayanan database \& system admin, karena user harus mengantri dan menunggu data cukup lama.

Pihak database \& system admin juga kadang kewalahan menangani permintaan data yang datang bersamaan dan banyak dari berbagai divisi, dimana mereka diminta untuk menyelesaikan permintaan data dengan cepat, tetapi data yang diberikan harus akurat dan sesuai dengan permintan user.

Pihak manajer juga kesulitan dalam proses evaluasi dan monitoring permintaan data dari user. Karena semuanya dilakukan manual dari email. Padahal manajer perlu melakukan evaluasi dan mengawasi divisi mana saja yang paling sering melakukan permintaan data, berapa banyak jumlah permintaan data setiap bulannya, berapa lama waktu pengerjaan permintaan data, berapa banyak yang pengerjaan permintaan data memakan waktu berhari-hari.

Untuk mengatasi semua permasalahan diatas, maka dibuatlah sistem informasi berbasis web yang digunakan sebagai aplikasi permintaan data dari berbagai divisi. Pada aplikasi ini, user bisa langsung melakukan penarikan data sendiri secara otomatis. Penarikan data tersebut adalah data rutin yang sering diminta pada database \& system admin. User bisa meminta kepada pihak database \& system admin, data apa saja yang mau mereka tarik sendiri, sehingga bisa dimasukkan ke aplikasi dan mereka bisa mengunduh secara otomatis.

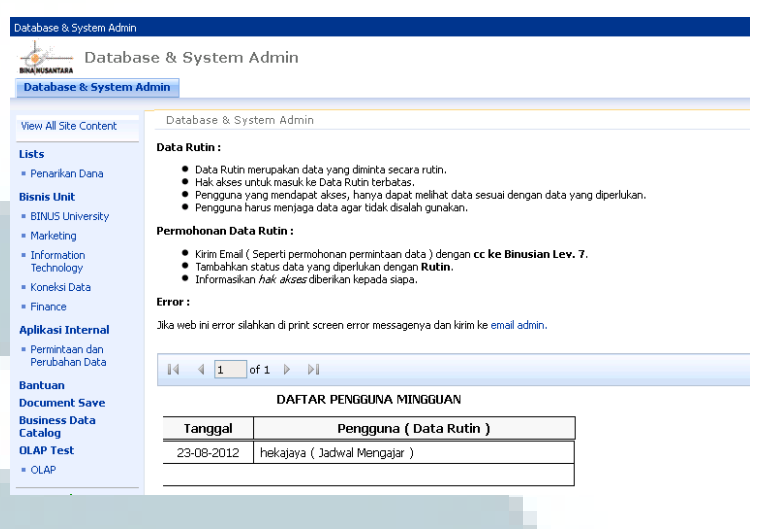

Gambar 3. Website Permintaan Data - Menu Home

Dengan adanya aplikasi ini, maka saat pihak user memerlukan data, mereka bisa mengunduh sendiri melalui web, tanpa perlu mengirim email dan meminta bantuan pihak database \& system admin. Data bisa di export kedalam file excel, word, pdf, csv, xml, dan html. Sehingga proses kebutuhan informasi menjadi lebih cepat, dan user bisa segera mengambil keputusan untuk mendukung proses bisnis mereka.

Berikut adalah contoh data pendaftar mahasiswa baru pada periode 2012, divisi admisi dan marketing bisa melakukan pengecekan siapa saja mahasiswa baru yang sudah daftar ulang ke Universitas XYZ dan jumlahnya.

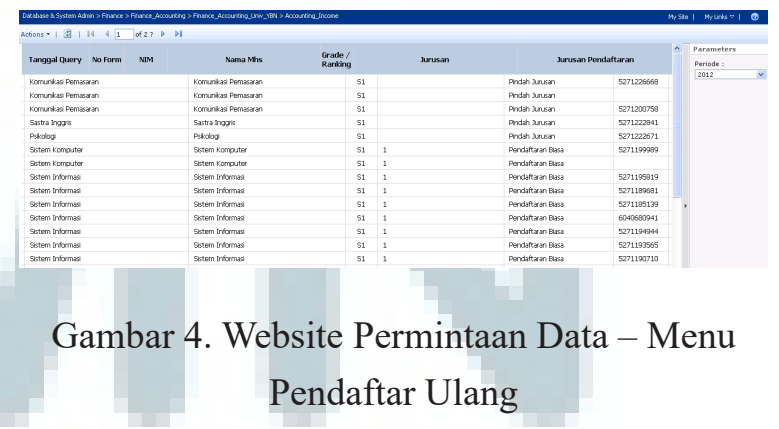

Bagi pihak database \& system admin, aplikasi ini membantu dalam meringankan pekerjaan sehari-hari mereka, sehingga saat ini database \& system admin fokus melayani 
permintaan data tidak rutin yang terdapat banyak customize sesuai permintaan user. Dengan adanya aplikasi ini, maka permintaan data melalui email juga berkurang.

Bagi manajer, mereka bisa melihat evaluasi dan monitoring permintaan data perbulannya. Pada laporan bisa terlihat divisi/bisnis unit mana saja yang paling sering melakukan permintaan data, jumlah permintaan data perbulan, dan waktu penyelesaian permintaan data perbulannya. Hal ini memudahkan manajer untuk membuat strategi yang sesuai agar proses bisnis bisa berjalan lebih efektif dan efisien. Memotong proses bisnis yang tidak perlu, sehingga mempercepat proses bisnis yang ada. Dengan proses laporan tersebut, maka manajer bisa melakukan montoring pencapaian KPI (Key Performance Indicator) pada divisi database \& system admin, sehingga jika KPI rendah bisa segera dilakukan tindakan untuk meningkatkan nilai KPI.

Berikut adalah tampilan laporan permintaan data untuk keperluan manajer melakukan evaluasi dan monitoring permintaan data. Laporan juga bisa disimpan dalam file, sehingga memudahkan manajer dalam menganalisa data.

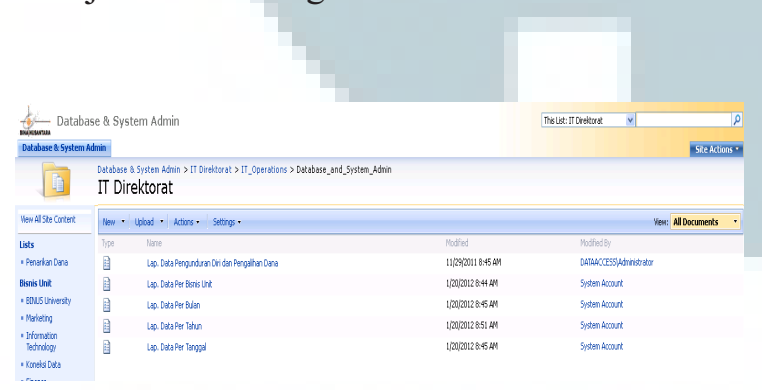

Gambar 5. Website Permintaan Data - Evaluasi \& Monitoring Permintaan Data

Dibawah ini adalah rekap laporan permintaan data per divisi/bisnis unit pada periode 2012:
Tabel 6. Rekap Laporan Permintaan Data
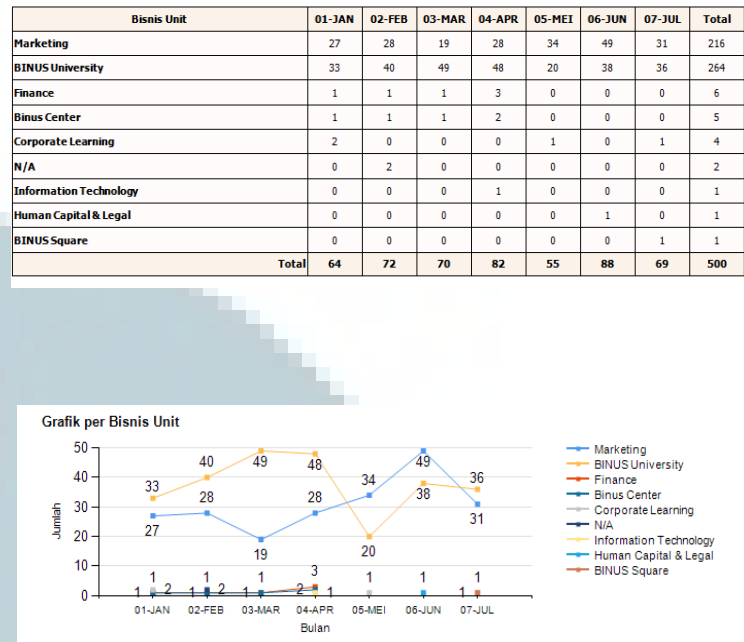

Gambar 6. Grafik Rekap Laporan Permintaan Data per Bisnis Unit per Bulan

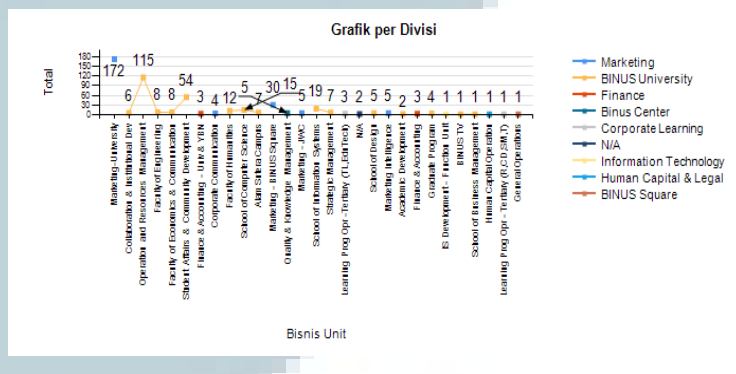

Gambar 7. Grafik Rekap Jumlah Laporan Permintaan Data per Bisnis Unit

Dibawah ini adalah rekap laporan permintaan data per bulan pada periode 2012 untuk monitoring waktu penyelesaian permintaan data : 

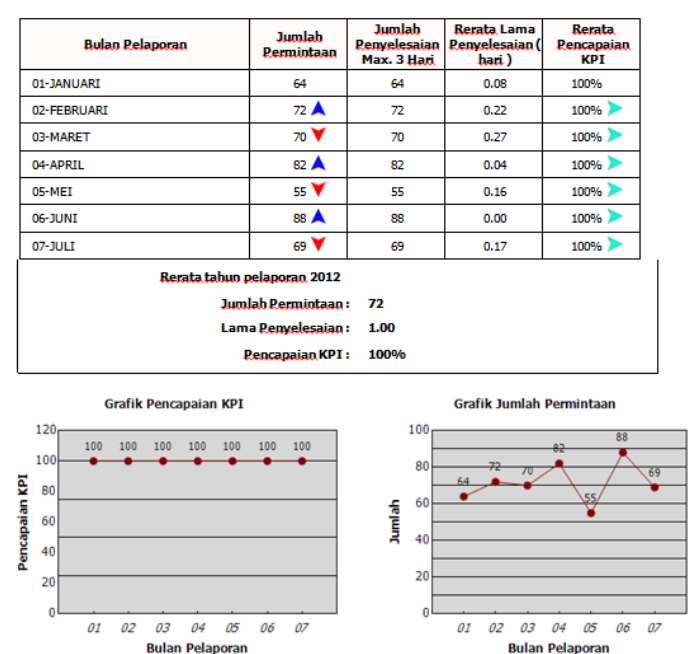

Gambar 8. Grafik Monitoring Waktu Penyelesaian Permintaan Data

\section{SIMPULAN DAN SARAN}

\subsection{Simpulan}

IT Balance Scorecard yang dipakai sudah mendukung pencapaian Balance Scorecard Universitas. Penggunaan IT Balance Scorecard menjadi panduan dan acuan bagi staf database \& system admin dalam melaksanakan pekerjaan untuk mendukung kegiatan operasional Universitas. IT Balance Scorecard juga sudah menjadi target KPI staf database \& system admin.

Sistem informasi yang dibuat sudah memberikan manfaat dalam menangani proses permintaan data pada Universitas XYZ, khususnya membantu divisi database \& system admin. Dengan adanya sistem informasi tersebut juga membantu manajer dalam proses monitoring KPI database \& system admin untuk mendukung tercapainya visi dan strategi Universitas $\mathrm{XYZ}$. Aplikasi tersebut juga sangat bermanfaat bagi user, sehingga memberikan informasi data yang cepat dan akurat. Dengan adanya aplikasi tersebut, proses bisnis dalam hal ini permintaan data untuk mendukung keperluan user menjadi lebih efektif dan efisien. Karena user bisa secara otomatis menarik data kapanpun dan dimanapun secara langsung sesuai kebutuhannya, tanpa harus menunggu dan meminta bantuan database
\& system admin. Aplikasi ini juga meringankan tugas staf database \& system admin, karena dengan adanya aplikasi ini, permintaan data melalui email menjadi berkurang.

Aplikasi permintaan data yang diimplementasi pada Universitas dibuat berdasarkan hasil output analisis IT Balance Scorecard. Jadi aplikasi digunakan untuk mendukung unit kerja dan pimpinan dalam mendapatkan dan akses data secara online, cepat, aman, dan reliable sebagai solusi dari masalah, mendukung pencapaian target, dan competitive advantages Universitas.

\subsection{Saran}

Saran yang diberikan penulis, untuk kedepannya adalah menambahkan tracking permintaan data dari user. Sehingga user bisa mendapatkan informasi status pengerjaan permintaan data mereka, siapa yang bertanggung jawab dalam proses pengerjaan permintaan tersebut, dan estimasi waktu pengerjaannya. Belum semua permintaan data dapat ditarik secara otomatis, harus dibuat sistem permintaan data yang lebih fleksibel, sehingga dapat memenuhi permintaan dan kebutuhan user. Aplikasi permintaan data juga harus dibuat dengan lebih interaktif dan informatif, sehingga dapat langsung digunakan untuk mendukung dalam pengambilan keputusan manajemen tanpa harus diolah lagi secara manual.

\section{DAFTAR PUSTAKA}

[1] H. Rubin, "Into the light: In CIO Magazine," akses Febuari 2015, http://www.cio.com. au/index.php/id;1718970659.

[2] R.S. Kaplan, dan D.P. Norton, "Translating Strategy into Action: The Balanced Scorecard," Harvard Business School Press, Boston, 1996.

[3] P.B. Seddon, "A Respecification and Extension of The DeLone and McLean model of ISSsuccess," Information Systems Research, vol. 8, no. 3, hal. 240-253, 1997.

\section{$90 \quad$ ULTIMA InfoSys, Vol. VI, No. 2 | Desember 2015}


[4] Campbell, Dennis, Datar, Srikant, Kulp, Cohen, Susan, dan V.G. Narayanan, "Using the Balanced Scorecard as a Control System for Monitoring and Revising Corporate Strategy," akses Febuari 2015, http: \www. ssrn.com.

[5] S. Modell, "Performance Measurement Myths in Public Sector", akses Febuari

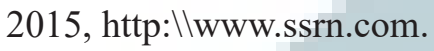

[6] Ittner, D. Christopher, dan D.F. Larcker, "Innovations in Performance Measurement: Trends and Research Implications", akses Febuari 2015, http: \www.ssrn.com.

[7] Hansen, R. Don, dan M.M. Mowen, "Management Accounting, 6th ed," SouthWestern, America, 2003.

[8] W.B. Tayler, "The Balanced Scorecard as a Strategy-Evaluation Tool: The Effects of Implementation Involvement and a CausalChain Focus," American Accounting Association, vol. 85, no. 3, hal. 1095-1117, 2010.
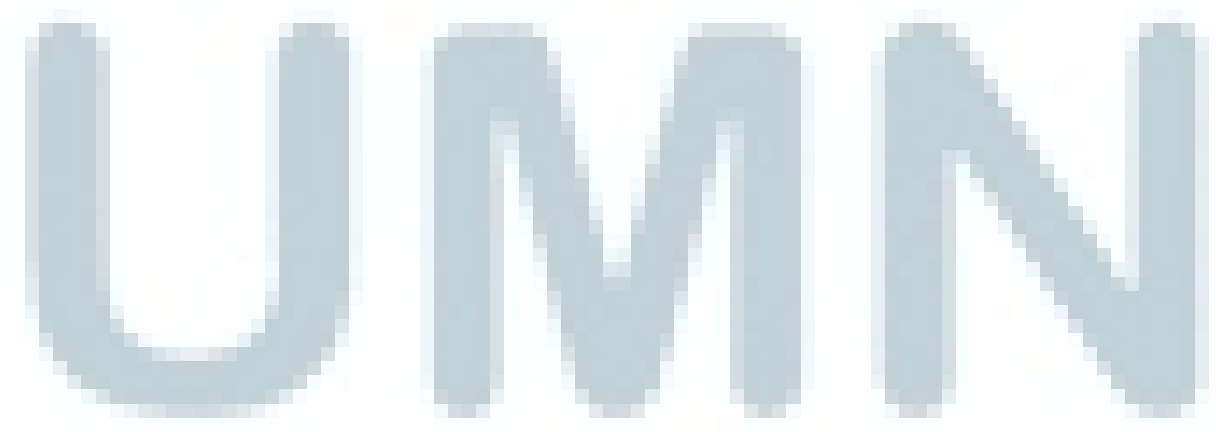